\title{
Oxymatrine attenuates bleomycin-induced pulmonary fibrosis in mice via the inhibition of inducible nitric oxide synthase expression and the TGF- $\beta /$ Smad signaling pathway
}

\author{
LEI LIU ${ }^{1,2}$, WEI LU ${ }^{3}$, ZHUANG MA ${ }^{2}$ and ZHENHUA LI ${ }^{1}$ \\ ${ }^{1}$ Institute of Respiratory Diseases, The First Affiliated Hospital of China Medical University, Shenyang $110001 ;{ }^{2}$ The Army \\ Center of Respiratory and Allergic Disease Diagnosis and Management, The General Hospital of Shenyang Military Region, \\ Shenyang 110016; ${ }^{3}$ Department of Respiratory Medicine, 202 Hospital of Chinese PLA, Shenyang 110003, P.R. China
}

Received December 22, 2011; Accepted February 1, 2012

DOI: $10.3892 / \mathrm{ijmm} .2012 .923$

\begin{abstract}
Oxymatrine (OM) is an alkaloid extracted from the Chinese herb Sophora flavescens Ait. with a variety of pharmacological activities. The aim of this study was to investigate the preventive effects of OM on bleomycin (BLM)-induced pulmonary fibrosis (PF) and to further explore the underlying mechanisms. C57BL/6 mice were randomly assigned to five groups: the saline sham group; the BLM group, in which mice were endotracheally instilled with BLM $(3.0 \mathrm{mg} / \mathrm{kg})$; and the BLM plus OM groups, in which OM was given to mice daily $(10,20$ or $40 \mathrm{mg} / \mathrm{kg})$ one day after BLM instillation for 21 days. The bronchoalveolar lavage fluid (BALF) and lung tissues were collected at 15 and 22 days post BLM administration, respectively. Lung tissues were stained with hematoxylin and eosin (H\&E) for histological evaluation. Levels of tumor necrosis factor (TNF)- $\alpha$, interleukin-6 (IL-6) and nitric oxide (NO) in mouse BALF were measured, as well as myeloperoxidase (MPO) activity and malondialdehyde (MDA) content in lung homogenates. The inducible nitric oxide synthase (iNOS) expression in the lung tissues was determined by immunohistochemical staining, quantitative real-time PCR and western blot analysis. Moreover, the expression of transforming growth factor (TGF)- $\beta 1, \mathrm{Smad} 2, \mathrm{Smad} 3, \mathrm{p}-\mathrm{Smad} 2$ and $\mathrm{p}-\mathrm{Smad} 3$ were also detected. We found that OM improved BLM-induced lung pathological changes, inhibited MPO
\end{abstract}

Correspondence to: Dr Zhenhua Li, Institute of Respiratory Diseases, The First Affiliated Hospital of China Medical University, 155 North Nanjing Street, Shenyang 110001, P.R. China

E-mail: zhenhua-li@163.com

Abbreviations: PF, pulmonary fibrosis; ECM, excessive extracellular matrix; OM, oxymatrine; BLM, bleomycin; NO, nitric oxide; TGF- $\beta$, transforming growth factor- $\beta$; iNOS, inducible nitric oxide synthase; BAL, bronchoalveolar lavage; BALF, bronchoalveolar lavage fluid; TNF- $\alpha$, tumor necrosis factor- $\alpha$; IL-6, interleukin-6; MPO, myeloperoxidase; MDA, malondialdehyde

Key words: pulmonary fibrosis, oxymatrine, bleomycin, nitric oxide synthase, TGF- $\beta /$ Smad signaling pathway activity and reduced MDA levels in a dose-dependent manner. OM also dose-dependently inhibited the release of TNF- $\alpha$ and IL-6, and decreased the expression of iNOS in lung tissues and thus prevented NO release in response to BLM challenge. In addition, OM decreased the expression of TGF- $\beta 1, \mathrm{p}-\mathrm{Smad} 2$ and p-Smad3, which are all important members of the TGF- $\beta$ / Smad signaling pathway. Our study provides evidence that OM significantly ameliorated BLM-induced PF in mice via the inhibition of iNOS expression and the TGF- $\beta /$ Smad pathway.

\section{Introduction}

Pulmonary fibrosis (PF) is a progressive and devastating disease that occurs as a result of diverse insults to the lungs, including toxic, autoimmune, drug-induced, infectious, and traumatic injuries. The pathology of PF is characterized by patchy chronic interstitial inflammation, excessive extracellular matrix (ECM) deposition, fibroblast proliferation, and collapse of alveoli, leading to progressive fibrosis and loss of lung functions (1-3). To date, despite extensive research efforts in experimental and clinical studies, PF remains an increasing cause of morbidity and mortality with an average survival of less than three years from diagnosis $(4,5)$. Conventional therapeutic strategies for PF include corticosteriods alone or in combination with other immunosuppressive agents; however, the efficacy of these agents is now being questioned, and longterm administration of glucocorticoids is often associated with several side effects, such as compromised immunity, peptic ulcer, hypertension, osteoporosis, endocrine and metabolic abnormalities $(1,6)$. Therefore, there is a compelling need to develop more effective and reliable therapeutic modalities for the treatment of PF.

Oxymatrine (OM) is a bioactive alkaloid constituent derived from the traditional Chinese herb medicine Sophora flavescens Ait. (Kushen) that has been approved by the State Food and Drug Administration of China for treating hepatitis $\mathrm{B}(7,8)$. Cumulative evidence has suggested that OM possesses multiple biological and pharmacological properties, such as anti-inflammatory $(9-11)$, antitumor $(12,13)$, anti-apoptotic (14), antifibrotic (15), antioxidant (16), and antiarrhythmic activities (17). Chen et al (18) demonstrated that 
$\mathrm{OM}$ is able to attenuate bleomycin (BLM)-induced PF in mice, and this beneficial effect is associated with the inhibition of BLM-induced lung inflammation and lipid peroxidation and the reduction of fibroblast proliferation and collagen synthesis (18). Nonetheless, the exact mechanisms by which OM exerts its antifibrotic effects on PF have not been fully elucidated. A better understanding of the molecular mechanisms underlying the pharmacological actions of OM will greatly enhance its application in the clinic.

Nitric oxide (NO) is an endogenous short-lived free radical that plays a crucial role in a number of lung diseases, including $\mathrm{PF}(19,20)$. It is synthesized by three isoforms of NO synthase (NOS): neuronal (nNOS), endothelial (eNOS), and inducible (iNOS) isoforms (21). Previous studies have demonstrated that upregulation of iNOS-induced NO production appears in PF in both animal models and humans (22-24). Transforming growth factor- $\beta 1$ (TGF- $\beta 1$ ) is well recognized as a key pro-fibrogenetic cytokine in $\mathrm{PF}$, and may result in collagen overproduction and deposition in the lung (25). Elevated expression of TGF- $\beta 1$ has also been found in the lung tissues of patients and animals with PF (26).

On the basis of the above-mentioned findings, we hypothesized that the antifibrotic therapeutic benefit mediated by $\mathrm{OM}$ during BLM-induced PF occurs via the inhibition of iNOS expression and the TGF- $\beta$ signaling pathway.

\section{Materials and methods}

Animals and drugs. Six- to eight-week-old male C57BL/6 mice were obtained from the Experimental Animal Center of China Medical University. They were housed at room temperature under a 12/12 h light/dark cycle, with free access to food and water. All mice were acclimatized to their new surroundings for one week prior to the experimental procedures. The animal experimental protocol was approved by the Ethics Committee of China Medical University, and all the animal studies were conducted in accordance with the NIH Guide for the Care and Use of Laboratory Animals. BLM was purchased from Meilun Biotechnology Co., Ltd. (Dalian, China), and OM was obtained from Guanyu Biotechnology Co., Ltd. (Xi'an, China).

BLM-induced PF model and animal treatment. BLM-induced $\mathrm{PF}$ was established in mice according to a method previously described, with minor modifications (27). In brief, mice were anesthetized with an intraperitoneal injection of chloral hydrate $(300 \mathrm{mg} / \mathrm{kg})$ and then subjected to a tracheostomy. BLM was instilled intratracheally at a dose of $3.0 \mathrm{mg} / \mathrm{kg}$ bodyweight in $100 \mu 1$ normal saline. An upright spin was then performed to ensure a homogeneous distribution of BLM to the mouse lungs. The sham mice received an equal volume of normal saline instead of BLM.

OM (with a purity $>98 \%$ ) was dissolved in physiological saline and intraperitoneally injected one day after BLM instillation. Fifty mice were randomly assigned to five experimental groups, with ten mice per group, as follows: the sham group, which was subjected to intratracheal instillation of normal saline and received intraperitoneal injections of vehicle; the BLM group, which was instilled intratracheally with BLM and received vehicle treatment; and the OM groups, which were subjected to intratracheal instillation of BLM and treated with
OM at doses of 10,20 or $40 \mathrm{mg} / \mathrm{kg}$. The selected doses of OM were based on the previous study by Chen et al (18). Mice were treated with intraperitoneal injection of OM or physiological saline once daily for 21 days.

Fifteen days after BLM instillation, five mice from each group were anesthetized with chloral hydrate $(300 \mathrm{mg} / \mathrm{kg}$, i.p.), and a bronchoalveolar lavage (BAL) was performed through a tracheal cannula using $2.0 \mathrm{ml}$ aliquots of normal saline for a total of $6.0 \mathrm{ml}$ for each mouse. The recovered BAL fluid (BALF) was then centrifuged at $1,000 \mathrm{x} \mathrm{g}$ for $10 \mathrm{~min}$ at $4^{\circ} \mathrm{C}$ and the resultant cell-free supernatant was stored at $-80^{\circ} \mathrm{C}$ for further analysis. Twenty-two days after BLM instillation, the remaining mice in each group were sacrificed to collect the lung tissues. The lung tissues were divided into two pieces, one immersed in $10 \%$ formalin solution for histopathological examination and immunohistochemistry, and the other part in liquid nitrogen for quantitative real-time PCR or western blot analysis.

Enzyme-linked immunosorbent assay (ELISA). Concentrations of tumor necrosis factor (TNF)- $\alpha$ and interleukin-6 (IL-6) in mouse BALF were measured with commercially available ELISA kits (R\&D Systems, Minneapolis, MN, USA) according to the manufacturer's instructions. In brief, diluted BALF samples were added to a microplate pre-coated with a monoclonal antibody specific for mouse TNF- $\alpha$ or IL-6. After washing to remove unbound substances, an enzyme-linked polyclonal antibody specific for mouse TNF- $\alpha$ or IL- 6 was added. After washing to remove unbound antibody-enzyme reagent, a substrate solution was added. The colored product yielded by the enzyme reaction was measured at $450 \mathrm{~nm}$ with an ELX 800 microplate reader (Bio-Tek Instruments, Inc., Winooski, VT, USA). The sample levels were calculated from a standard curve and expressed in $\mathrm{ng} / \mathrm{l}$.

$N O$ analysis in BALF. The pulmonary production of NO in the BALF was analyzed with a nitrate/nitrite colorimetric assay. Briefly, nitrate was converted to nitrite by nitrate reductase, and Griess reagent (1\% sulfanilic acid, $0.1 \%$ $\mathrm{N}-1$-naphthylethylenediamine dihydrochloride, $5 \%$ phosphoric acid; Jiancheng Bioengineering Institute, Nanjing, China) was added to the BALF, which converted nitrite to a deep-purple azo compound. The absorbance was measured at $550 \mathrm{~nm}$ using a plate absorbance reader (Bio-Tek Instruments, Inc.) and the nitrite concentration was determined using sodium nitrite as a standard.

Measurements of myeloperoxidase (MPO) activity and malon dialdehyde (MDA) and in lung tissues. Frozen lung tissues were thawed and homogenized in cold saline at a ratio of 1:19 $(w / v)$. Samples were centrifuged at $800 \mathrm{x}$ g for $10 \mathrm{~min}$ at $4^{\circ} \mathrm{C}$, and then the tissue supernatants were collected for biochemical measurements. MPO activity and MDA levels in lung tissues were determined by commercially available kits (Jiancheng Bioengineering Institute). For MPO activity, the supernatants were incubated with hydrogen peroxide in the presence of O-dianisidine dihydrochloride $(0.167 \mathrm{mg} / \mathrm{ml})$ for $30 \mathrm{~min}$. The change in absorbance at $460 \mathrm{~nm}$ for each sample was recorded with a microplate reader (Bio-Tek Instruments, Inc.). MPO activity was defined as the quantity of enzyme degrading 
$1 \mu \mathrm{mol}$ peroxide per minute at $37^{\circ} \mathrm{C}$ and is expressed in $\mathrm{U} / \mathrm{g}$ lung tissue. MDA content was determined based on the reaction of MDA with thiobarbituric acid at $90-100^{\circ} \mathrm{C}$. Levels of MDA are expressed as nmol/mg protein.

Lung histopathology. Histopathological examination was performed on mice that were not subjected to BAL. Lung tissues were fixed in $10 \%(\mathrm{w} / \mathrm{v})$ neutral-buffered formalin for $24 \mathrm{~h}$, dehydrated in a graded ethanol series, and subsequently embedded in paraffin. Sequential $5 \mu \mathrm{m}$ sections of the lungs were placed on slides and stained with routine hematoxylin and eosin (H\&E) for morphological analysis using a standard protocol. The slides were then investigated under a light microscope (BA400 Binocular Microscope; Motic, Xiamen, China).

Immunohistochemistry. Lung tissues were fixed in $10 \%$ buffered formalin for $24 \mathrm{~h}$, embedded in paraffin, and cut into $5-\mu \mathrm{m}$ sections. The sections were pretreated at $60^{\circ} \mathrm{C}$ for $2 \mathrm{~h}$, then dewaxed in xylene, hydrated, and washed in $0.01 \mathrm{~mol} / 1$ phosphate-buffered saline (PBS, $\mathrm{pH}$ 7.2) solution. Antigen retrieval was performed at $100^{\circ} \mathrm{C}$ for $10 \mathrm{~min}$ in a $10 \mathrm{mmol} / 1$ citrate buffer ( $\mathrm{pH} 6.0$ ), and endogenous peroxidase activity was quenched by using $3 \%$ hydrogen peroxide (v/v) in methanol for $15 \mathrm{~min}$ at room temperature. After rinsing in a $0.01 \mathrm{~mol} / \mathrm{l}$ PBS solution, non-specific protein binding was eliminated by blocking with $10 \%$ normal goat serum. Subsequently, the tissue sections were incubated with a polyclonal antibody against mouse iNOS (1:200 diluted; Biosynthesis Biotechnology Co., Ltd., Beijing, China) overnight at $4^{\circ} \mathrm{C}$. Negative controls were achieved by omitting the primary antibody. The sections were then incubated for $30 \mathrm{~min}$ in secondary antibody (1:200 biotinylated goat anti-rabbit immunoglobulin $\mathrm{G}(\mathrm{IgG})$; Zhongshan Golden Bridge Biotechnology Co., Ltd., Beijing, China), followed by incubation for $30 \mathrm{~min}$ with streptavidinhorseradish peroxidase conjugate. Finally, reaction products were visualized with 3,3'-diaminobenzidine (DAB) and then counterstained with hematoxylin.

$R N A$ isolation and quantitative real-time PCR. Total-RNA was isolated from lung tissues using the RNA simple totalRNA kit (Tiangen Biotechnology Co., Ltd., Beijing, China), and was dissolved in RNase-free water. The concentration and purity of RNA was determined by calculating the ratio of the absorbance at 260 and $280 \mathrm{~nm}$. RNA integrity was assessed by comparing the relative intensities of the 18 and $28 \mathrm{~S}$ ribosomal RNA bands as detected under ultraviolet radiation after electrophoresis and staining with GoldView dye (Sbsgene, Shanghai, China). Equal amounts of RNA (1 $\mu \mathrm{g})$ from each sample were reverse-transcribed in a volume of $20 \mu 1$ to synthesize complementary DNA (cDNA) using the TIANScript RT kit (Tiangen Biotechnology Co., Ltd.). Reverse transcription reactions were carried out at $42^{\circ} \mathrm{C}$ for $50 \mathrm{~min}$ and $95^{\circ} \mathrm{C}$ for $5 \mathrm{~min}$. Quantitative real-time PCR reactions were performed in $20 \mu \mathrm{l}$ reaction mixture containing $10 \mu \mathrm{l}$ of SYBR-Green Master Mix (Tiangen Biotechnology Co., Ltd.), $0.5 \mu \mathrm{M}$ of forward and reverse primers, and $1 \mu \mathrm{l}$ template cDNA on an Exicycler ${ }^{\mathrm{TM}} 96$ real-time quantitative thermal block (Bioneer, Daejeon, Korea). The primers were designed according to the mouse iNOS and glyceraldehyde-3-phosphate dehydrogenase (GAPDH) gene sequences reported in GenBank, and were synthesized by Sangon Biotechnology Co., Ltd. (Shanghai, China). The sequences of the primers were as follows: iNOS, forward, 5'-GCAGGGAATCTTGGAGCGAGTTG-3' and reverse, 5'-GTAGGTGAGGGCTTGGCTGAGTG-3'; GAPDH, forward, 5'-TGTTCCTACCCCCAATGTGTCCGTC-3' and reverse, 5'-CTGGTCCTCAGTGTAGCCCAAGATG-3'. All reactions were incubated at $95^{\circ} \mathrm{C}$ for $5 \mathrm{~min}$, followed by 35 cycles of $95^{\circ} \mathrm{C}$ for $10 \mathrm{sec}, 60^{\circ} \mathrm{C}$ for $20 \mathrm{sec}$, and $72^{\circ} \mathrm{C}$ for $30 \mathrm{sec}$. A melting curve was generated at the end of every run to ensure product uniformity. GAPDH was used in parallel as an internal control to normalize samples. PCR reactions were conducted in triplicate. Data were analyzed through the comparative threshold cycle $\left(\mathrm{C}_{\mathrm{T}}\right)$ method (28).

Western blot analysis. Lung tissues were homogenized in ice-cold radioimmunoprecipitation (RIPA) lysis buffer (Beyotime Institute of Biotechnology, Haimen, China). After centrifugation $\left(12,000 \mathrm{xg}, 10 \mathrm{~min}\right.$ at $\left.4^{\circ} \mathrm{C}\right)$, the supernatant was collected and protein concentration was determined using a bicinchoninic acid (BCA) protein assay kit (Beyotime Institute of Biotechnology) with bovine serum albumin as the standard. Equal amounts of proteins $(40 \mu \mathrm{g})$ were separated on $10 \%$ sodium dodecyl sulfate polyacrylamide gels (SDS-PAGE) and then transferred electrophoretically onto polyvinylidene difluoride (PVDF) membranes (Millipore, Bedford, MA, USA). The blotted membranes were blocked with $5 \%$ non-fat dry milk (w/v) in Tris-buffered saline with $0.1 \%$ Tween-20 (TBS-T), and then incubated at $4^{\circ} \mathrm{C}$ overnight with anti-iNOS (1:500 diluted), anti-TGF- $\beta 1$ (1:1,000 diluted), anti-Smad2 (1:1,000 diluted), anti-phospho-Smad2 (1:1,000 diluted), anti-Smad3 (1:4,000 diluted), anti-phospho-Smad3 (1:4,000 diluted) (all from Biosynthesis Biotechnology Co., Ltd.), or anti- $\beta$-actin (1:10,000 diluted; Kangcheng, Shanghai, China) antibodies. After six rinses with TBS-T at $5 \mathrm{~min}$ intervals, the membranes were incubated for $45 \mathrm{~min}$ with horseradish peroxidase-labeled goat anti-rabbit $\operatorname{IgG}(1: 5,000$ diluted; Biosynthesis Biotechnology Co., Ltd.). Immunodetection was performed with enhanced chemiluminescence (ECL; Millipore) and exposed on an X-ray film. $\beta$-actin was used as an internal reference for relative quantification. Densitometric analysis of the immunoblots was performed using the Gel-Pro 3.0 software.

Statistical analysis. All data are presented as the means \pm standard deviation (SD). One-way ANOVA followed by the Bonferroni post hoc test was used to compare the differences among multiple groups. All statistical analyses were performed using the SPSS 13.0 software package (SPSS Inc., Chicago, IL, USA). P-value $<0.05$ was considered to indicate a statistically significant difference.

\section{Results}

Effects of OM on BLM-induced lung histopathological changes. Histopathological abnormalities in the lungs were evaluated at 21 days after OM treatment with H\&E staining. The morphology of the lung tissues from the sham mice displayed normal alveolar spaces and normal thickening of the alveolar septa under a light microscope (Fig. 1A). However, the lungs from mice with BLM and vehicle treatment showed 

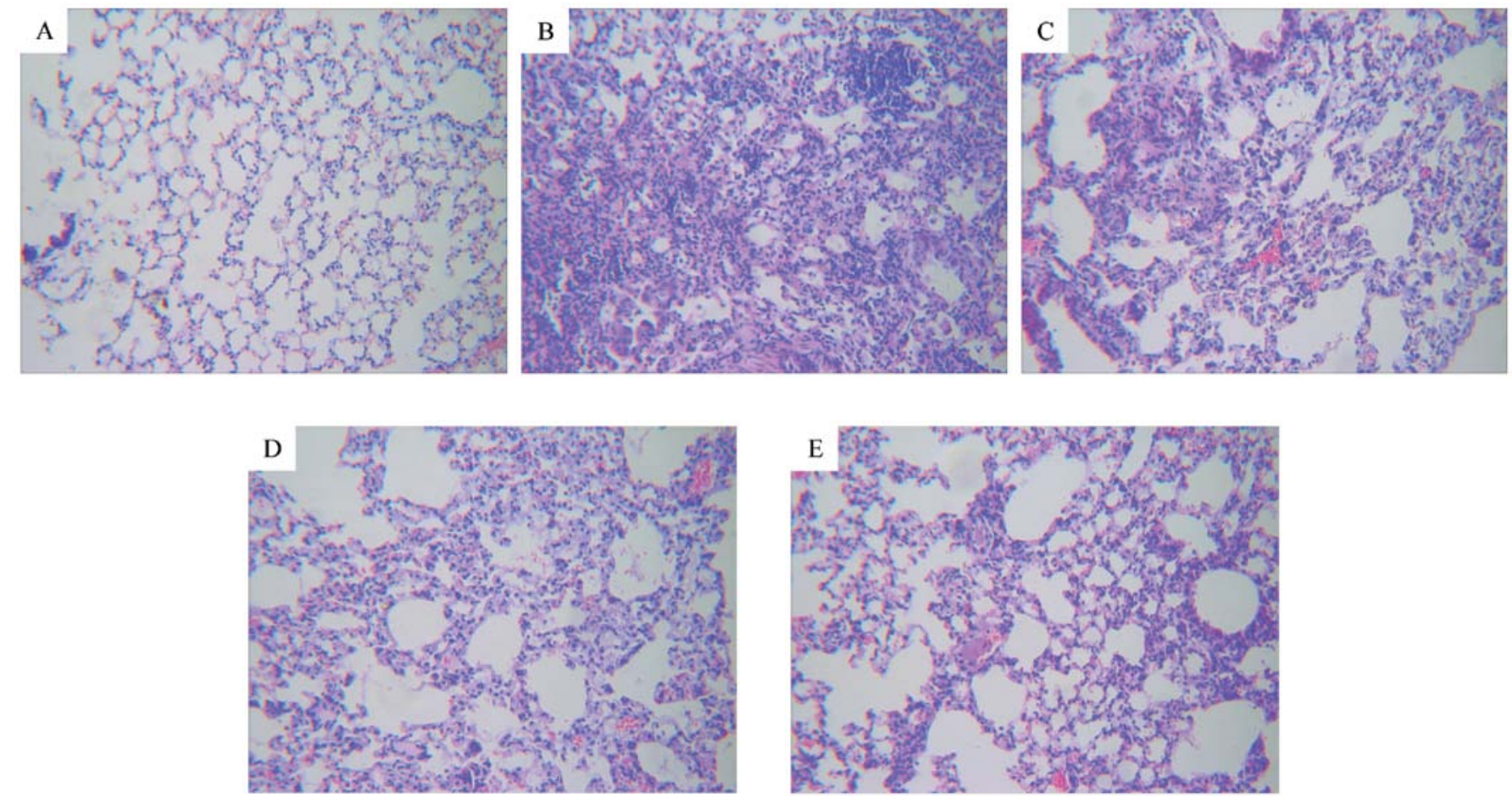

Figure 1. Effects of oxymatrine (OM) on bleomycin (BLM)-mediated lung histopathogical changes. Mice were instilled intratracheally with $3.0 \mathrm{mg} / \mathrm{kg}$ BLM or the equal amount of normal saline. Some BLM-exposed mice were then intraperitoneally injected with $10,20 \mathrm{or} 40 \mathrm{mg} / \mathrm{kg}$ OM one day after BLM instillation. (A) The lungs of mice were prepared for histological analysis 22 days after the BLM challenge. Lung section from the sham mice instilled intratracheally with saline. (B) Lung section from BLM-induced PF model mice. Lung section from the mice exposed to BLM and then administered (C) $10 \mathrm{mg} / \mathrm{kg}$, (D) $20 \mathrm{mg} / \mathrm{kg}$ or (E) $40 \mathrm{mg} / \mathrm{kg}$ OM. Representative histological section of the lungs was stained by hematoxylin and eosin (H\&E staining, x200).

A

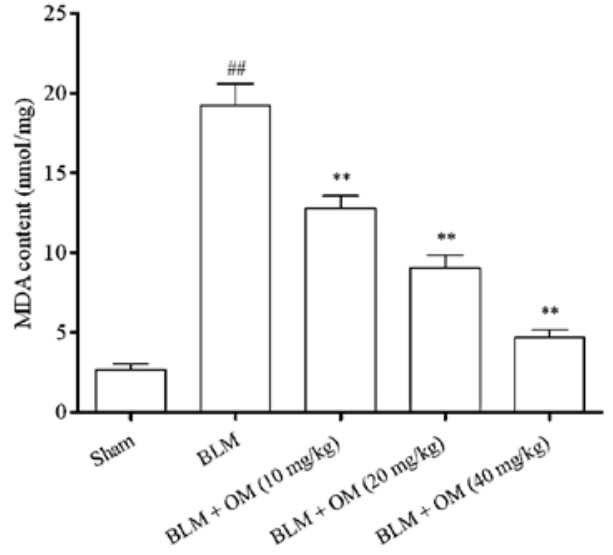

B

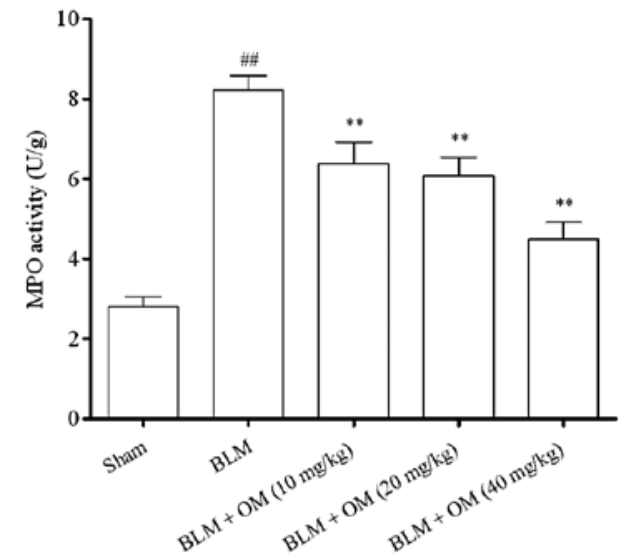

Figure 2. Effects of oxymatrine (OM) on the (A) malondialdehyde (MDA) content and (B) myeloperoxidase (MPO) activity in the lungs of bleomycin (BLM)induced pulmonary fibrosis (PF) mice. Mice were treated with intraperitoneal injection of different doses of OM once daily for 21 days. Data are presented as the mean $\pm \mathrm{SD}(\mathrm{n}=5) .{ }^{\# \#} \mathrm{P}<0.01$ vs. the sham group; ${ }^{* * *} \mathrm{P}<0.01$ vs. the BLM group.

marked histopathological abnormalities, such as disturbed alveolar structure, extensive thickening of the interalveolar septa, and dense interstitial infiltration by lymphocytes, neutrophils and fibroblasts (Fig. 1B). By contrast, treatment with all three doses of OM resulted in moderate amelioration of inflammatory cell infiltration, together with a reduction in interstitial thickening (Fig. 1C-E).

Effects of OM on MDA levels and MPO activity in the lung tissues of BLM-treated mice. Twenty-two days after BLM instillation, the level of MDA, an index of lipid peroxidation, was significantly increased in vehicle-treated lung tissues from $2.66 \pm 0.35$ to $19.2 \pm 1.39 \mathrm{nmol} / \mathrm{mg}$ protein $(\mathrm{P}<0.01, \mathrm{n}=5)$, compared to that in the sham controls (Fig. 2A). Following administration of OM $(10,20,40 \mathrm{mg} / \mathrm{kg})$, the BLM-induced lipid peroxidation was evidently decreased to $12.78 \pm 0.79$ $(\mathrm{P}<0.01, \mathrm{n}=5), 9.06 \pm 0.79(\mathrm{P}<0.01, \mathrm{n}=5), 4.71 \pm 0.45 \mathrm{nmol} / \mathrm{mg}$ protein $(\mathrm{P}<0.01, \mathrm{n}=5)$, respectively, in comparison to the BLM group. Moreover, MPO activity, a marker of neutrophil influx into the tissue, was measured (Fig. 2B). Compared to the sham group, treatment of mice with BLM resulted in a dramatic elevation of MPO activity from $2.81 \pm 0.24$ to $8.23 \pm 0.35 \mathrm{U} / \mathrm{g}$ 
A

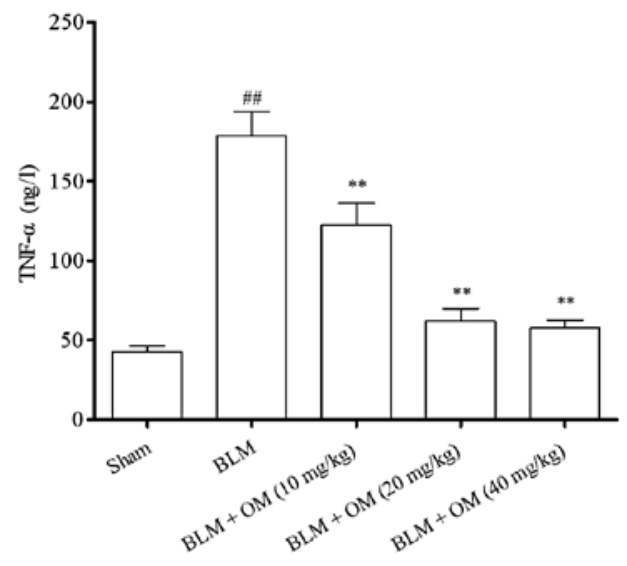

B

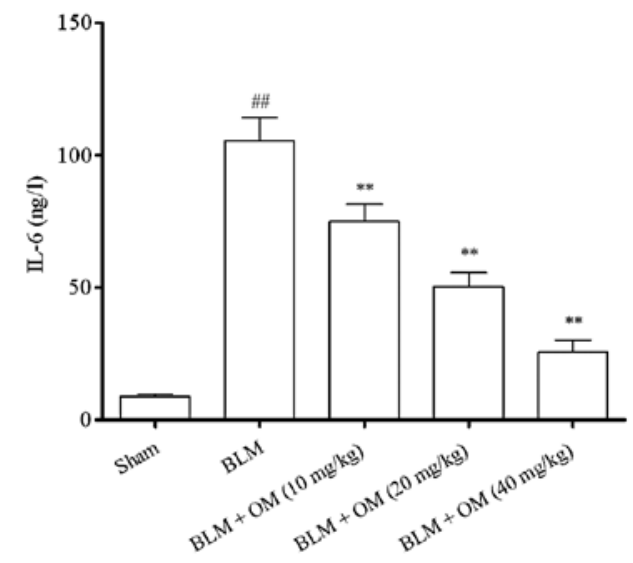

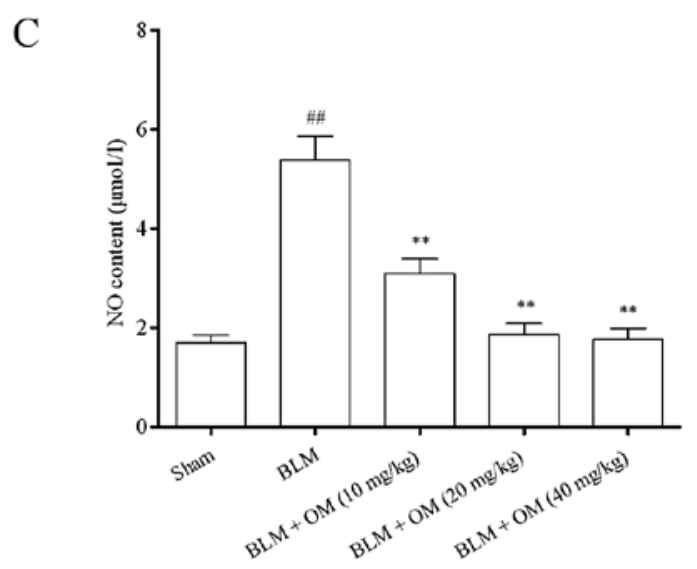

Figure 3. Effects of oxymatrine (OM) on the (A) TNF- $\alpha$, (B) IL-6 and (C) NO levels in the bronchoalveolar lavage fluid (BALF) of bleomycin (BLM)-induced pulmonary fibrosis $(\mathrm{PF})$ mice. Data are expressed as the mean $\pm \mathrm{SD}(\mathrm{n}=5) .{ }^{\# \#} \mathrm{P}<0.01$ vs. the sham group; ${ }^{* *} \mathrm{P}<0.01$ vs. the BLM group.

protein $(\mathrm{P}<0.01, \mathrm{n}=5)$. However, treatment with $\mathrm{OM}(10,20$, $40 \mathrm{mg} / \mathrm{kg}$ ) significantly attenuated the increase from $8.23 \pm 0.35$ to $6.37 \pm 0.55(\mathrm{P}<0.01, \mathrm{n}=5)$, from $8.23 \pm 0.35$ to $6.07 \pm 0.47$ $(\mathrm{P}<0.01, \mathrm{n}=5)$, and from $8.23 \pm 0.35$ to $4.49 \pm 0.42(\mathrm{P}<0.01$, $\mathrm{n}=5$ ), respectively.

Effects of OM on inflammatory cytokines in the BALF of $B L M$-treated mice. Concentration of TNF- $\alpha$ and IL-6 in the BALF represents proinflammatory mediators, which were thought to play important roles in the pathogenesis of PF. As shown in Fig. 3A and B, we found that TNF- $\alpha$ and IL-6 were only minimally expressed in the sham mice. Two weeks after BLM instillation, a substantial increase in TNF- $\alpha$ and IL-6 levels was observed in the BALF. However, these levels decreased dose-dependently with OM administration $(\mathrm{P}<0.01, \mathrm{n}=5)$.

NO derived from iNOS is an important toxic molecule regarding tissue injury. We measured the NO content in the BALF of BLM-treated mice. NO level was increased in the BLM-induced PF model mice compared to the mice in the sham group (Fig. 3C). OM treatment significantly suppressed the BLM-induced rise of NO levels in the BALF $(\mathrm{P}<0.01$, $\mathrm{n}=5$ ). This inhibitory effect was dose-dependent.

Effects of OM on iNOS expression in the lungs of BLM-treated mice. Previous studies have demonstrated an increased level of $\mathrm{NO}$ in the BALF and an overexpression of iNOS in the lungs during the development of BLM-induced PF in mice (24). To determine whether OM inhibits NO production via the suppression of iNOS expression, we investigated the expression levels of iNOS in lung tissues. The photomicrographs of the immunohistochemical localization of iNOS in lung tissues are shown in Fig. 4. In the sham group, positive signals for iNOS were weakly found in a small number of alveolar macrophages (Fig. 4A). Twenty-two days after BLM instillation, positive signals for iNOS were observed prominently in alveolar epithelial cells, alveolar macrophages and microvascular endothelial cells (Fig. 4B). However, OM at the dose of 20 and $40 \mathrm{mg} / \mathrm{kg}$ significantly attenuated the BLM-induced rise of iNOS expression in the lung tissues (Fig. 4D and E), while almost no reduction in iNOS expression was shown by $10 \mathrm{mg} / \mathrm{kg}$ OM (Fig. 4C).

To further determine the iNOS expression in BLM-induced PF mice, iNOS mRNA and protein levels were measured by quantitative real-time PCR and western blot analysis, respectively. Compared with the sham group, there was a marked increase in iNOS mRNA levels in the BLM group. OM administration dose-dependently attenuated the increase of iNOS mRNA in the lung tissues of mice with BLM-induced $\mathrm{PF}(\mathrm{P}<0.01, \mathrm{n}=5)$. Meanwhile, changes observed by western blot analysis were in accordance with the findings in the quantitative real-time PCR study (Fig. 5). These data indicated that OM inhibits NO production via the suppression of iNOS expression in BLM-induced PF mice. 

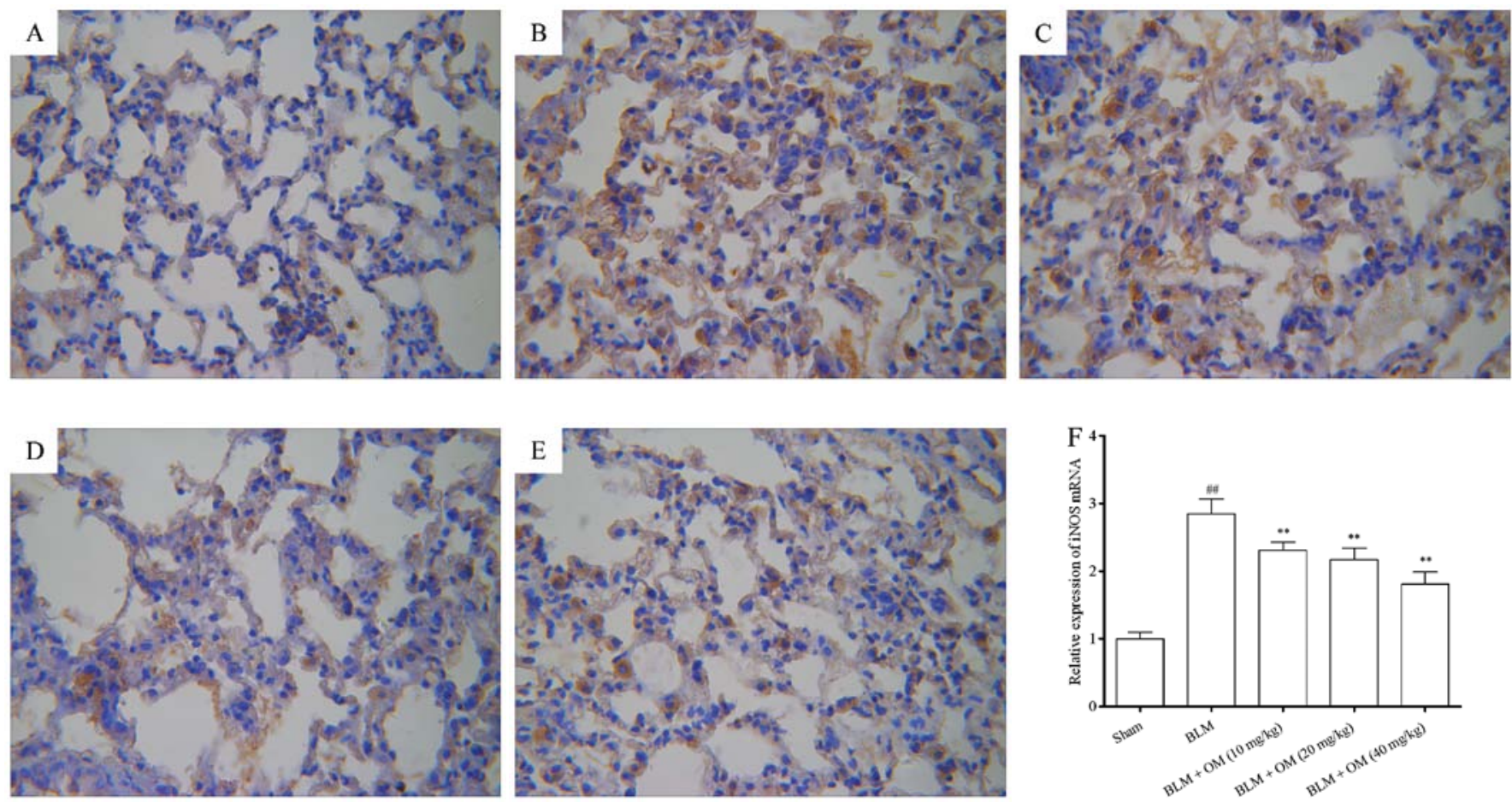

Figure 4. Effects of oxymatrine (OM) on the expression of iNOS in the lungs of BLM-induced PF mice as shown by immunohistochemical staining (A-E) and quantitative real-time PCR (F). (A) Lung section from the sham mouse, (B) Bleomycin (BLM)-induced pulmonary fibrosis (PF) mice, and the mice exposed to BLM and then treated with an intraperitoneal injection of (C) $10 \mathrm{mg} / \mathrm{kg}$, (D) $20 \mathrm{mg} / \mathrm{kg}$, (E) $40 \mathrm{mg} / \mathrm{kg}$ OM once daily for 21 days. Original magnification, $\mathrm{x} 400$. (F) Data are the mean $\pm \mathrm{SD}(\mathrm{n}=5)$. ${ }^{\# \prime} \mathrm{P}<0.01$ vs. the sham group; ${ }^{* *} \mathrm{P}<0.01$ vs. the BLM group.

A

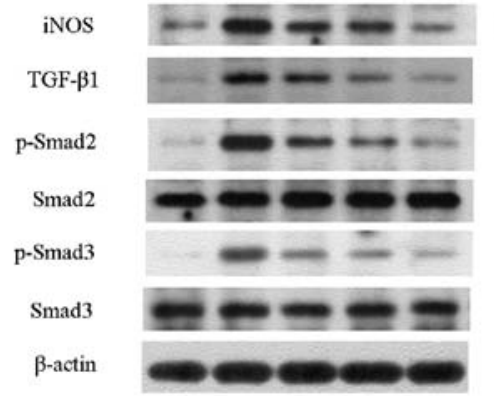

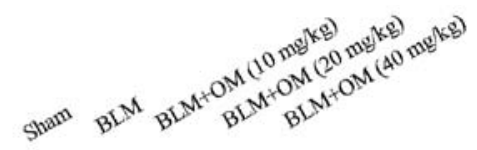

$130 \mathrm{kDa}$

$44 \mathrm{kDa}$

$52 \mathrm{kDa}$

$52 \mathrm{kDa}$

$47 \mathrm{kDa}$

$47 \mathrm{kDa}$

$43 \mathrm{kDa}$
B

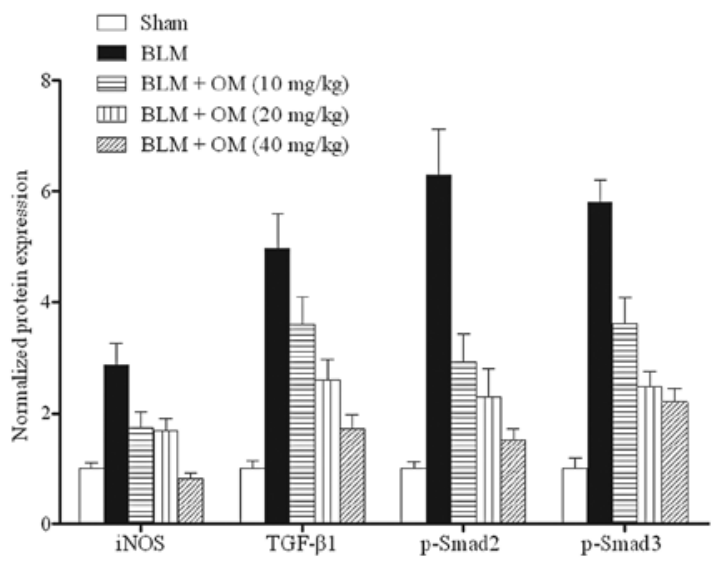

Figure 5. Western blot analysis of TGF- $\beta 1$, Smad2 and Smad3, phosphorylation of Smad2 and Smad3 and iNOS levels in the lungs of bleomycin (BLM)induced pulmonary fibrosis (PF) mice. (A) Representative blots are shown and protein size is expressed in kDa. (B) Densitometric quantification data are expressed as the intensity ratio of target proteins to $\beta$-actin (mean $\pm \mathrm{SD}, \mathrm{n}=5$ ).

Effects of OM on TGF- $\beta 1$ expression and phosphorylation of Smad 2 and Smad 3 in the lung tissues of BLM-treated mice. TGF- $\beta 1$ has been shown to play a key role in the process of PF by increasing the synthesis and secretion of ECM proteins while inhibiting matrix degradation (29). To investigate whether OM exerts its anti-fibrotic effects through inhibiting the TGF- $\beta /$ Smad pathway in BLM-induced PF, we first detected the protein expression of TGF- $\beta 1$ in the lung tissues of BLM-treated mice. BLM instillation significantly increased TGF- $\beta 1$ protein expression in the lung tissues, which was dose-dependently downregulated by OM treatment (Fig. 5) $(\mathrm{P}<0.01, \mathrm{n}=5)$. Since phosphorylation of Smad signaling by the activated TGF- $\beta 1$ receptor $\mathrm{I}$ is a major step in the initiation of TGF- $\beta$ signal transduction, we further examined the activation of Smad2 and Smad3 in the lungs of BLM-treated mice. Phosphorylation of Smad2 and Smad3 was increased in the BLM group compared with the sham group, as confirmed by western blot analysis with phosphorylated antibodies of Smad2 and Smad3, respectively (Fig. 5). Treatment with OM markedly inhibited these BLM-activated signaling molecules in a dose-dependent fashion. These observations suggest that $\mathrm{OM}$ protects mice against BLM-induced $\mathrm{PF}$, at least in part, via the inhibition of the TGF- $\beta /$ Smad pathway. 


\section{Discussion}

BLM is an antitumor antibiotic used for the therapy of a variety of cancers, and PF is a well-known side effect in patients treated with BLM. Intratracheal instillation of BLM into the lungs of rodents causes alveolar cell damage, an inflammatory response, fibroblast proliferation and subsequent collagen deposition as seen in human PF $(30,31)$. Therefore, this animal model has been widely used to mimic the pathologic features of human PF and to investigate novel pharmacological approaches for preventing PF $(32,33)$. In the present investigation, we have demonstrated that $\mathrm{OM}$ at a dose of 10,20 or $40 \mathrm{mg} / \mathrm{kg}$ exerts anti-inflammatory and antifibrotic actions in lungs of mice exposed to BLM, as evidenced by the attenuation of morphological fibrotic responses and the decreases in lipid peroxidation (MDA levels) and neutrophil infiltration (MPO activity). Meanwhile, OM dose-dependently attenuated concentrations of pro-inflammatory mediators such as NO, TNF- $\alpha$ and IL-6 in the BALF. In addition, OM effectively repressed the TGF- $\beta 1$ expression and the activation of Smad2 and Smad3, which was associated with the inhibition of the TGF- $\beta$ /Smad pathway, and this may represent an additional mechanism by which OM exerts its antifibrotic effects.

Oxidative stress plays a key role in the BLM-induced pulmonary inflammation and fibrosis since excess levels of reactive oxygen species (ROS) can non-specifically oxidize cellular macromolecules such as DNAs, lipids, and proteins, leading to oxidative stress-induced tissue injury $(34,35)$. BLM is known to produce ROS during the process of reaction with DNA, thereby causing direct injuries to lung cells and matrix (31). In this study, we found that BLM instillation induced a marked increase in lipid peroxidation as reflected by the MDA level, and this level was significantly decreased by $\mathrm{OM}$ treatment in a dose-dependent manner. We postulate that $\mathrm{OM}$ has antioxidant activities due to the hydroxyl group in its structure (36). MPO activity has been used as a marker of neutrophil influx into the tissue (37). Herein, we observed that OM treatment significantly inhibited the increase of MPO activity due to BLM administration, suggesting that OM may suppress the migration of neutrophils in the inflamed region, thereby ameliorating tissue damage in the lung. These findings are consistent with a previous report from Chen et al (18), who also showed that OM effectively inhibited the MDA levels and MPO activity in a mouse model of BLM-induced PF. Based on the findings, it is reasonable to conclude that $\mathrm{OM}$ is an effective free radical scavenger capable of repressing reactive oxygen radicals and decreasing neutrophil recruitment into the lungs.

Although the underlying pathophysiology of PF remains elusive, excessive cytokine-mediated inflammation was generally believed to play a predominant role in the progression of PF. Clinical evidence has indicated that the concentration of cytokines was increased in the BALF of patients with PF (38). Additionally, there is a significant body of evidence demonstrating that BLM induces inflammatory cells to secrete multifunctional cytokines, such as TNF- $\alpha$, IL-6 and IL-1 $\beta$ (30). In the present study, we consistently found that BLM administration markedly increased the concentration of TNF- $\alpha$ and IL-6 in the BALF of BLM-induced PF mice. By contrast, OM treatment significantly reduced the pro-inflammatory cytokine levels in the BALF. Our results are in agreement with previous studies showing anti-inflammatory effects of $\mathrm{OM}$ in other diseases. For example, Zhang et al (11) have demonstrated that OM effectively reduces the serum TNF- $\alpha$ level in rats with L-arginine-induced acute pancreatitis. It has also been shown that OM is able to reduce neuronal cell apoptosis by inhibiting Toll-like receptor 4/nuclear factor $\kappa$-B-dependent inflammatory responses in traumatic rat brain injury (14). Collectively, we concluded that $\mathrm{OM}$ may protect mice against BLM-induced PF by decreasing the production or activities of these pro-inflammatory cytokines.

BLM has been shown to be a stimulator of iNOS expression and NO over-production (39-41). Increased pulmonary expression of iNOS and increased NO production are observed in PF patients; however, no changes in the levels of other NOSs have been detected $(22,42)$. In addition, pharmacological inhibition of NO has been proposed as a potential therapeutic strategy for PF (23). These findings support the notion that NO overproduced by iNOS formation may have deleterious effects in the pathogenesis of PF. In the current study, we found that OM treatment dose-dependently reduced BLM-induced increment of iNOS expression and subsequent NO production. Our results provide evidence that the antifibrotic effects of $\mathrm{OM}$ may be mediated by the downregulation of iNOS. However, the precise mechanism whereby OM inhibits iNOS expression needs to be further elucidated.

As the most relevant profibrotic cytokine in PF, TGF- $\beta 1$ plays a vital role in the synthesis and accumulation of collagen and fibronectin in the lungs (43). A number of experimental studies have reported that the inhibition of TGF- $\beta$ by antiTGF- $\beta$ antibodies, decorin, TGF- $\beta$ soluble receptors, or a peptide inhibitor of TGF- $\beta$, has a protective effect on the development of PF (44-47). Zhao et al (48) have also demonstrated that Smad3 deficiency attenuates bleomycin-induced PF in mice. In the present study, OM treatment effectively inhibited the expression of TGF- $\beta 1$ and the BLM-activated Smad 2 and Smad3, which is consistent with previous studies showing that amelioration of fibrosis is often associated with the inhibition of the TGF- $\beta /$ Smad signaling pathway (49-52). Moreover, our results are also in agreement with the findings of $\mathrm{Wu}$ et al (15) who found that OM has antifibrotic effects in the liver via the inhibition of the TGF- $\beta /$ Smad pathway (15). Taken together, our observations indicate that the antifibrotic effect of $\mathrm{OM}$ in BLM-induced PF may be partly due to the inhibition of the TGF- $\beta /$ Smad pathway.

In conclusion, the present study demonstrated that $\mathrm{OM}$ could attenuate BLM-induced PF in mice via the inhibition of pro-inflammatory cytokine expression and the TGF- $\beta$ / Smad pathway. In addition, OM prevented NO overproduction through reducing iNOS expression in mouse lungs. Our results suggest that OM may be a promising candidate for the prevention of BLM-induced lung damage or other interstitial PF.

\section{References}

1. Gross TJ and Hunninghake GW: Idiopathic pulmonary fibrosis. N Engl J Med 345: 517-525, 2001.

2. Thannickal VJ, Toews GB, White ES, Lynch JP III and Martinez FJ: Mechanisms of pulmonary fibrosis. Annu Rev Med 55: 395-417, 2004.

3. Garantziotis S, Steele MP and Schwartz DA: Pulmonary fibrosis: thinking outside of the lung. J Clin Invest 114: 319-321, 2004 
4. American Thoracic Society. Idiopathic pulmonary fibrosis: diagnosis and treatment. International consensus statement. American Thoracic Society (ATS), and the European Respiratory Society (ERS). Am J Respir Crit Care Med 161: 646-664, 2000.

5. Raghu G, Collard HR, Egan JJ, et al: An official ATS/ERS/JRS/ ALAT statement: idiopathic pulmonary fibrosis: evidence-based guidelines for diagnosis and management. Am J Respir Crit Care Med 183: 788-824, 2011.

6. Bouros D and Antoniou KM: Current and future therapeutic approaches in idiopathic pulmonary fibrosis. Eur Respir J 26 693-702, 2005

7. Xu WS, Zhao KK, Miao XH, et al: Effect of oxymatrine on the replication cycle of hepatitis B virus in vitro. World J Gastroenterol 16: 2028-2037, 2010.

8. Wang YP, Zhao W, Xue R, et al: Oxymatrine inhibits hepatitis $B$ infection with an advantage of overcoming drug-resistance. Antiviral Res 89: 227-231, 2011.

9. Zhao J, Yu S, Tong L, et al: Oxymatrine attenuates intestinal ischemia/reperfusion injury in rats. Surg Today 38: 931-937, 2008

10. Fan H, Li L, Zhang X, et al: Oxymatrine downregulates TLR4, TLR2, MyD88, and NF-kappaB and protects rat brains against focal ischemia. Mediators Inflamm 2009: 704706, 2009.

11. Zhang Z, Wang Y, Dong M, Cui J, Rong D and Dong Q Oxymatrine ameliorates L: -arginine-induced acute pancreatitis in rats. Inflammation: Jun 2, 2011 (Epub ahead of print).

12. Zhang Y, Piao B, Hua B, et al: Oxymatrine diminishes the side population and inhibits the expression of beta-catenin in MCF-7 breast cancer cells. Med Oncol 28: (Suppl 1): S99-S107, 2010.

13. Ling Q, Xu X, Wei X, et al: Oxymatrine induces human pancreatic cancer PANC-1 cells apoptosis via regulating expression of Bcl-2 and IAP families, and releasing of cytochrome c. J Exp Clin Cancer Res 30: 66, 2011.

14. Dong XQ, Yu WH, Hu YY, Zhang ZY and Huang M: Oxymatrine reduces neuronal cell apoptosis by inhibiting Toll-like receptor 4/nuclear factor kappa-B-dependent inflammatory responses in traumatic rat brain injury. Inflamm Res 60: 533-539, 2011.

15. Wu XL, Zeng WZ, Jiang MD, Qin JP and Xu H: Effect of Oxymatrine on the TGFbeta-Smad signaling pathway in rats with CCl4-induced hepatic fibrosis. World J Gastroenterol 14: 2100-2105, 2008.

16. Li M, Zhang X, Cui L, et al: The neuroprotection of oxymatrine in cerebral ischemia/reperfusion is related to nuclear factor erythroid 2-related factor 2 (nrf2)-mediated antioxidant response: role of nrf 2 and hemeoxygenase-1 expression. Biol Pharm Bull 34: 595-601, 2011

17. Cao YG, Jing S, Li L, et al: Antiarrhythmic effects and ionic mechanisms of oxymatrine from Sophora flavescens. Phytother Res 24: 1844-1849, 2010.

18. Chen X, Sun R, Hu J, et al: Attenuation of bleomycin-induced lung fibrosis by oxymatrine is associated with regulation of fibroblast proliferation and collagen production in primary culture. Basic Clin Pharmacol Toxicol 103: 278-286, 2008.

19. Hsu YC, Wang LF and Chien YW: Nitric oxide in the pathogenesis of diffuse pulmonary fibrosis. Free Radic Biol Med 42: 599-607, 2007.

20. Ricciardolo FL, Sterk PJ, Gaston B and Folkerts G: Nitric oxide in health and disease of the respiratory system. Physiol Rev 84 731-765, 2004

21. Marletta MA: Nitric oxide synthase: aspects concerning structure and catalysis. Cell 78: 927-930, 1994.

22. Saleh D, Barnes PJ and Giaid A: Increased production of the potent oxidant peroxynitrite in the lungs of patients with idiopathic pulmonary fibrosis. Am J Respir Crit Care Med 155: 1763-1769, 1997.

23. Hobbs AJ, Higgs A and Moncada S: Inhibition of nitric oxide synthase as a potential therapeutic target. Annu Rev Pharmacol Toxicol 39: 191-220, 1999.

24. Gurujeyalakshmi G, Wang Y and Giri SN: Suppression of bleomycin-induced nitric oxide production in mice by taurine and niacin. Nitric Oxide 4: 399-411, 2000.

25. Coker RK, Laurent GJ, Jeffery PK, du Bois RM, Black CM and McAnulty RJ: Localisation of transforming growth factor betal and beta3 mRNA transcripts in normal and fibrotic human lung. Thorax 56: 549-556, 2001.

26. Khalil N and Greenberg AH: The role of TGF-beta in pulmonary fibrosis. Ciba Found Symp 157: 194-211, 1991.

27. Jules-Elysee $\mathrm{K}$ and White DA: Bleomycin-induced pulmonary toxicity. Clin Chest Med 11: 1-20, 1990.
28. Livak KJ and Schmittgen TD: Analysis of relative gene expression data using real-time quantitative PCR and the 2(-Delta Delta C(T)) method. Methods 25: 402-408, 2001.

29. Xu M, Deng B, Chow YL, Zhao ZZ and Hu B: Effects of curcumin in treatment of experimental pulmonary fibrosis: a comparison with hydrocortisone. J Ethnopharmacol 112: 292-299, 2007.

30. Scheule RK, Perkins RC, Hamilton R and Holian A: Bleomycin stimulation of cytokine secretion by the human alveolar macrophage. Am J Physiol 262: L386-L391, 1992.

31. Hay J, Shahzeidi S and Laurent G: Mechanisms of bleomycininduced lung damage. Arch Toxicol 65: 81-94, 1991.

32. Moeller A, Ask K, Warburton D, Gauldie J and Kolb M: The bleomycin animal model: a useful tool to investigate treatment options for idiopathic pulmonary fibrosis? Int J Biochem Cell Biol 40: 362-382, 2008

33. Mouratis MA and Aidinis V: Modeling pulmonary fibrosis with bleomycin. Curr Opin Pulm Med 17: 355-361, 2011.

34. Bargagli E, Olivieri C, Bennett D, Prasse A, Muller-Quernheim J and Rottoli P: Oxidative stress in the pathogenesis of diffuse lung diseases: a review. Respir Med 103: 1245-1256, 2009.

35. Kinnula VL, Fattman CL, Tan RJ and Oury TD: Oxidative stress in pulmonary fibrosis: a possible role for redox modulatory therapy. Am J Respir Crit Care Med 172: 417-422, 2005.

36. Song G, Luo Q, Qin J, Wang L, Shi Y and Sun C: Effects of oxymatrine on proliferation and apoptosis in human hepatoma cells. Colloids Surf B Biointerfaces 48: 1-5, 2006.

37. Serrano-Mollar A, Closa D, Cortijo J, et al: P-selectin upregulation in bleomycin induced lung injury in rats: effect of N-acetyl-Lcysteine. Thorax 57: 629-634, 2002.

38. Vasakova M, Sterclova M, Kolesar L, et al: Cytokine gene polymorphisms and BALF cytokine levels in interstitial lung diseases. Respir Med 103: 773-779, 2009.

39. Galuppo M, Di Paola R, Mazzon E, et al: GW0742, a high affinity PPAR-beta/delta agonist reduces lung inflammation induced by bleomycin instillation in mice. Int J Immunopathol Pharmacol 23: 1033-1046, 2010

40. Di Paola R, Talero E, Galuppo M, et al: Adrenomedullin in inflammatory process associated with experimental pulmonary fibrosis. Respir Res 12: 41, 2011.

41. Galuppo M, Esposito E, Mazzon E, et al: MEK inhibition suppresses the development of lung fibrosis in the bleomycin model. Naunyn Schmiedebergs Arch Pharmacol 384: 21-37, 2011.

42. Lakari E, Soini Y, Saily M, Koistinen P, Paakko P and Kinnula VL: Inducible nitric oxide synthase, but not xanthine oxidase, is highly expressed in interstitial pneumonias and granulomatous diseases of human lung. Am J Clin Pathol 117: 132-142, 2002.

43. Bartram $\mathrm{U}$ and Speer $\mathrm{CP}$ : The role of transforming growth factor beta in lung development and disease. Chest 125: 754-765, 2004

44. Giri SN, Hyde DM and Hollinger MA: Effect of antibody to transforming growth factor beta on bleomycin induced accumulation of lung collagen in mice. Thorax 48: 959-966, 1993.

45. Giri SN, Hyde DM, Braun RK, Gaarde W, Harper JR and Pierschbacher MD: Antifibrotic effect of decorin in a bleomycin hamster model of lung fibrosis. Biochem Pharmacol 54: 1205-1216, 1997.

46. Kolb M, Margetts PJ, Galt T, et al: Transient transgene expression of decorin in the lung reduces the fibrotic response to bleomycin. Am J Respir Crit Care Med 163: 770-777, 2001.

47. Arribillaga L, Dotor J, Basagoiti M, et al: Therapeutic effect of a peptide inhibitor of TGF-beta on pulmonary fibrosis. Cytokine 53: 327-333, 2011.

48. Zhao J, Shi W, Wang YL, et al: Smad3 deficiency attenuates bleomycin-induced pulmonary fibrosis in mice. Am J Physiol Lung Cell Mol Physiol 282: L585-L593, 2002.

49. Ou XM, Li WC, Liu DS, et al: VEGFR-2 antagonist SU5416 attenuates bleomycin-induced pulmonary fibrosis in mice. Int Immunopharmacol 9: 70-79, 2009.

50. Chen L, Wang T, Wang X, et al: Blockade of advanced glycation end product formation attenuates bleomycin-induced pulmonary fibrosis in rats. Respir Res 10: 55, 2009.

51. Zhao L, Wang X, Chang Q, et al: Neferine, a bisbenzylisoquinline alkaloid attenuates bleomycin-induced pulmonary fibrosis. Eur J Pharmacol 627: 304-312, 2010.

52. Gao J, Huang Y, Li P, et al: Antifibrosis effects of total glucosides of Danggui-Buxue-Tang in a rat model of bleomycin-induced pulmonary fibrosis. J Ethnopharmacol 136: 21-26, 2011. 